\title{
Designing Effective Health Education Interventions for Preventing Obesity in South Asian Americans
}

\author{
Manoj Sharma \\ University of Cincinnati
}

\begin{abstract}
South Asian Americans constitute the fastest growing immigrant group in the United States. Overweight (adults: 38\% - 57\%, children: 18\% - 43\%) and obesity (24\%) rates in Asian Americans are increasing and not even a single health education intervention has been designed for this group in this regard. The purpose of this study was to identify culturally-relevant determinants that influence obesity and overweight among South Asian Americans and develop a set of recommendations for designing culturally-appropriate interventions for this group. The modifiable determinants for overweight and obesity in South Asian Americans were found to be physical inactivity, dietary behaviors (consuming large portion sizes, less consumption of fruits and vegetables, large consumption of sweetened beverages), watching TV for long hours on a sustained basis, acculturation to the US, poor family communication, less social support, less social integration, stress, and longer years of living in the United States. There is need for interventions both for children in school settings utilizing parental involvement and for adults in community settings utilizing local religious organizations. Culturally robust behavioral theories need to be utilized with this subpopulation.
\end{abstract}

(c) 2006 Californian Journal of Health Promotion. All rights reserved.

Keywords: Asian, Indian, overweight, obesity

\section{Introduction}

One of the fastest growing immigrant groups in the United States is from South Asia (Ahmed, \& Lemkau, 2000). South Asia or the Indian subcontinent, as the region is often referred to, consists of the countries of India, Pakistan, Sri Lanka, Bangladesh, Nepal, and Bhutan. These countries have been differentiated from Far East (Japan, China etc.) and South East Asian (Malaysia, Thailand, Singapore etc.) countries in the literature (Aspinall, 2003). There is considerable heterogeneity within the people represented in South Asia but there are several similarities in the culture that the people from this region share allowing for this group to be considered as a single unit for purposes of health programming (Ahmed, \& Lemkau, 2000).

In the 2000 U.S. Census, about 12 million people in the United States or $4.2 \%$ of the population were classified as Asians comprising of people who were Asians alone or Asians in combination with other races (Barnes, \&
Bennett, 2002). In the 1990 U.S. Census data on Asian and Pacific Islander "alone" category was collected and was found to be 6.9 million (United States Census Bureau, 1990). The population of Asian "alone" category in the 2000 U.S. Census increased to 10.2 million or an increase of 48 percent (Barnes, \& Bennett, 2002). Over half (51\%) of the Asian population lived in California, New York, and Hawaii (United States Census Bureau, 2005). Asian Indians are the third largest group of Asians after Chinese and Filipinos with these three groups accounting for 58 percent of the total Asians. In the 2000 U.S. Census, about 1.7 million people reported their race as Asian Indian alone and another 0.2 million reported Asian Indian in combination with another race. In addition, there were about 57,000 people from Bangladesh, 200 people from Bhutan, 9,000 from Nepal, 200,000 from Pakistan, and 24,000 from Sri Lanka (United States Census Bureau, 2005). Asian Indians are underrepresented in American health literature (Misra, Patel, Davies, 
\& Russo, 2000). While there has still been some research with some Asian groups such as Japanese, Chinese, and Filipinos not much data is available with regard to Asian Indians (Kar, Campbell, Jimenez, \& Gupta, 1995).

Providing health services and culturallysensitive health education to South Asians is a major challenge. Overweight and obesity have reached an epidemic proportion in the United States with $61 \%$ of the adults being overweight or obese in 1999 (United States Department of Health \& Human Services [USDHHS], 2001). It is estimated that 300,000 deaths are attributed to obesity (Allison, Fontaine, Manson, Stevens, VanItallie, 1999). Overweight and obesity are associated with coronary heart disease, several types of cancers, type 2 diabetes, stroke, arthritis, breathing disorders, and psychological disorders including depression (USDHHS, 2001). In immigrant Asian Indians, prevalence of hypertension (12-20\%), diabetes $(6-8 \%)$ and coronary heart disease $(7-14 \%)$ has been found to be higher than native rural Indians residing In India and Western populations (Singh, Tomlinson, Thomas, \& Sharma, 2001). The national health care expenditures, in the United States, related to overweight and obesity in adults are estimated between $\$ 98$ billion to $\$ 129$ billion (Institute of Medicine, 2004). Not many studies have been done with South Asian Americans for estimating the prevalence of overweight and obesity, or understanding culturally-relevant determinants, or testing culturally-appropriate health education and promotion interventions. Hence, the purpose of this study was to identify culturally-relevant determinants that influence obesity and overweight among South Asian Americans and develop a set of recommendations for designing culturally-appropriate interventions for this group.

\section{Methodology}

In order to collect the materials for the study a search of ERIC, CINAHL, and PubMed databases was done. The inclusion criteria for selection of articles in this study were articles: 1) published in English language, 2) published in or after 1995, 3) that were peer-reviewed, 4) that dealt with prevalence or determinants, or interventions for overweight or obesity, and 5) that involved Asian American subpopulation. The search was not restricted to South Asian American community because that would not have yielded enough articles. Excluded from this analysis were: 1) publications in other languages, 2) publications other than peerreviewed journal articles such as reports, news items etc., 3) articles published prior to 1994 , and 4) articles on aspects of health other than overweight or obesity. A total of 32 journal articles met the criteria and have been included in this study.

\section{Prevalence of Overweight and Obesity}

National data is not found with regard to prevalence of overweight and obesity for AsianAmerican groups (Crawford, Story, Wang, Ritchie, \& Sabry, 2001). Furthermore, in many studies diverse populations such as Asians and Pacific Islanders have been clubbed together into one group (Davis et al., 2004). The other problem in the data pertains to the cut-off point for classifying overweight and obesity. Body mass index (BMI) is often used for defining overweight (BMI $\geq 25 \mathrm{~kg} / \mathrm{m}^{2}$ ) and obesity (BMI $\geq 30 \mathrm{~kg} / \mathrm{m}^{2}$ ) in the United States. For Asian populations the use of these BMI cut-offs has been questioned as these do not correlate well with percent body fat and other risks such as heart disease, hypertension, glucose intolerance, and lipid profiles.

A study done with Chinese, Malay, and Indian ethnic groups found that body fat was elevated at lower BMI's for all three ethnic groups (Deurenberg-Yap \& Deurenberg, 2003). Based on similar studies it has been recommended that BMI cut-off value for Asians be lower (Deurenberg, Deurenberg-Yap, \& Guricci, 2002; Steering Committee of the International Diabetes Institute, [SCIDI], 2000). However, a few studies have found that BMI does compare well with Western assumptions especially for North Indian men (Bhansali, Nagaprasad, Agarwal, Dutta, \& Bhadada, 2005). In any case the recommendations for Asians are lower than Western populations and for overweight are $\mathrm{BMI} \geq 23 \mathrm{~kg} / \mathrm{m} 2$ and for obesity $\mathrm{BMI} \geq 25 \mathrm{~kg} / \mathrm{m}^{2}$ (SCIDI, 2000). A study by Shah and colleagues (2005) in Asian Indian Americans for metabolic 
syndrome and a study Vikram and colleagues (2003) in diabetics also recommended use of lower cutoff values. A study by Wang and colleagues (1996) done in New York City found that Asian Americans had the lowest BMI but $63 \%$ of them had fat percent above the median values as compared to Caucasians in both genders again justifying lower cut off values. Denney and colleagues (2004) have advocated for having specific guidelines for different subpopulations. Unfortunately, there is not enough awareness in health functionaries in the United States about these guidelines who continue to monitor Asians using Western guidelines.

A cross-sectional survey using data from 199295 National Health Interview Survey (NHIS) was analyzed to examine body mass index (BMI) in Asian Americans including Indian Americans (Lauderdale \& Rathouz, 2000). Using standard Western cutoffs, it was found that $57 \%$ of the males and $38 \%$ of the females were overweight. Twenty-five percent Asian Indian women were overweight and were the largest subsection in women. The overall percentage of obese Asian Americans was very less. After adjusting for age and ethnicity it was found that BMI was $1.31 \mathrm{~kg} / \mathrm{m}^{2}$ less for foreign born than native born Asian American men and likewise it was $1.14 \mathrm{~kg} / \mathrm{m}^{2}$ less for the two groups in women.

In a survey of elementary school children in New York city by Thorpe and colleagues (2004) it was found that prevalence of overweight was $43 \%(95 \%$ confidence interval $[\mathrm{CI}]=39 \%$, $47 \%)$ and obesity was $24 \%(95 \% \mathrm{CI}=21 \%$, $27 \%$ ). Asian children were found to have the lowest level of obesity among all racial/ethnic groups $(14.4 \%, 95 \% \mathrm{CI}=10.9,18.7)$. Again standard cutoffs were used and data about South Asian American children was not available from this study. Further, the study did not include private schools that enroll over $20 \%$ students. Many South Asian Americans who value education are more likely to admit their children in private schools which were missed by this survey.

A survey of children among users of community health centers revealed a prevalence of overweight using standard cutoffs as 18.2\% (95\% CI: 11.2 - 28.3) among Asian Americans (Stettler, Elliott, Kallan, Auerbach, \& Kumanyika, 2005). The prevalence rates were not any different when compared to Hispanics, non Hispanic Blacks, or non Hispanic white children. Data specific to South Asian community was not available from this study.

Gordon-Larsen and colleagues (2003) studied the data from 13,113 U.S. adolescents from grades 7-12 enrolled in the National Longitudinal Study of Adolescent Health and found the prevalence of overweight in Asian American male teens as $22.8 \%$ and female teens as $10.4 \%$ and they noted several disparities between ethnic groups. Using logistic regression modeling they were able to demonstrate that even if income and education were equalized, the health disparities would not be eliminated thus underscoring the need for addressing environmental, contextual, biological, and sociocultural factors in health programming.

\section{Determinants of Overweight and Obesity}

Overweight and obesity are caused by various factors. Body weight is shaped by a combination of genetic, metabolic, behavioral, environmental, cultural, and socioeconomic influences. In health education and health promotion we are primarily interested in modifiable behavioral, cultural, and environmental factors. For a large majority of individuals, overweight and obesity result from excess calorie consumption and/or inadequate physical activity (United States Department of Health \& Human Services, 2001). For South Asian American community, several factors were found to be important and modifiable. These have been summarized in Table 1 . 
Table 1

Modifiable factors for overweight and obesity in South Asian American population

\begin{tabular}{|l|l|l|}
\hline \multicolumn{1}{|c|}{ Category of Factor } & \multicolumn{1}{|c|}{ Factor } & \multicolumn{1}{|c|}{ Subcategories of Factor } \\
\hline Behavioral factors & Physical inactivity & \\
\hline \multirow{2}{*}{} & Dietary behaviors & Large portion sizes \\
\cline { 3 - 3 } & & $\begin{array}{l}\text { Less consumption of fruits } \\
\text { and vegetables }\end{array}$ \\
\cline { 3 - 3 } & $\begin{array}{l}\text { Large consumption of } \\
\text { sweetened beverages }\end{array}$ \\
\hline Cultural factors & $\begin{array}{l}\text { Watching TV for long } \\
\text { hours on a sustained basis }\end{array}$ & \\
\hline & Acculturation to the US & \\
\hline Environmental factors & Poor family communication & \\
\hline & Less social support & \\
\hline & Less social integration & \\
\hline & Stress & \\
\hline & Years in the United States & \\
\hline
\end{tabular}

\section{Physical Inactivity}

Expert panel on detection, evaluation, and treatment of high blood cholesterol in adults (2001) in its third report of the National Cholesterol Education Program (NCEP) Adult Treatment Panel III (ATP III) has developed a set of criteria for identifying a condition called metabolic syndrome. Presence of three or more of the following components help in identification of metabolic syndrome: elevated waist circumference (men $\geq 40$ inches or $102 \mathrm{~cm}$; women $\geq 35$ inches or $88 \mathrm{~cm})$; elevated triglyceride $(\geq 150 \mathrm{mg} / \mathrm{dL})$; reduced HDL (men $\leq$ $40 \mathrm{mg} / \mathrm{dL}$; women $\leq 50 \mathrm{mg} / \mathrm{dL}$ ); elevated blood pressure $(\geq 130 / 85 \mathrm{~mm} \mathrm{Hg})$; and elevated fasting glucose $(\geq 110 \mathrm{mg} / \mathrm{dL})$. Misra and colleagues (2005) studied the relationship of intensity and duration of leisure time physical activity to the physiological indices of metabolic syndrome in Asian Indian immigrants. They found a prevalence of $33.9 \%$ of metabolic syndrome in their sample. Most people in their sample reported less leisure time physical activity. But it was found that men who were moderately active had lower physiological indices for metabolic syndrome and the study recommend more programs that promote physical activity in this group.
A cross-sectional survey by Misra and colleagues (2000) among Gujarati Asian Indians using Health Promotion Lifestyle Profile II (Walker, Sechrist, \& Pender, 1996) found lower scores for physical activity and nutrition for the whole group. Physical inactivity (sedentary behavior) was highest among people in the age group 25-50 years. Protective factors of interpersonal skills and spiritual growth were found to be high and can be used by health education programs.

A review of studies regarding physical activity behaviors among South Asian immigrants in the United Kingdom found lower levels of physical activity in all South Asian groups compared to the general population (Fischbacher, Hunt, \& Alexander, 2004). While this study was done in UK but a similar study done in the United States found similar results where Asian Americans, especially immigrants, were found to be at risk for low levels of Leisure time physical activity and high levels of sedentary behavior (Kandula \& Lauderdale, 2005). A study by Gordon-Larsen and colleagues (1999) using the nationally representative data from the 1996 National Longitudinal Study of Adolescent Health found that moderate to vigorous physical activity (five to eight metabolic equivalents) was lowest for 
female and minority adolescents including Asian Americans. Hence, promoting physical activity is a very significant and modifiable determinant for this subpopulation.

\section{Dietary Behaviors}

Dietary behaviors are very important for maintaining healthy body weight. Healthy eating that includes increased fruit and vegetable consumption, controlled portion size, and limited soft drink consumption is considered good for combating obesity (Gerberding \& Marks, 2004). Unfortunately, not many studies have been done with regard to dietary behaviors in Asian Americans leave alone South Asian Americans.

A study was done by Jonnalagadda, Diwan and Cohen (2005) to decipher dietary behaviors in Gujarati Asian Indian immigrants. The study found that the sample of immigrants studied did not meet the established U.S. dietary guidelines. It was found that both men and women met the daily number of servings recommendations for the grains (men: 9.3 servings/day; women: 6.9 servings/day) and vegetables (men: 4.5 servings/day; women: 3.6 servings/day) groups, but did not meet the recommendations for fruits, dairy and meats groups.

\section{Television Viewing}

Watching television (T.V.) for long hours on a sustained basis has been claimed to be associated with overweight and obesity especially in children. Robinson and Killen (1995) found a week association between weekly hours of television viewing and BMI in a sample that included Asian Americans. They also found television viewing to be associated with higher fat intake. A study by GordonLarsen and colleagues (2002) found TV/video viewing to be positively associated with overweight in a sample that included Asian Americans (among boys odds ratio $[\mathrm{OR}]=1.52$; 95\% CI: 1.08 to 2.14 and girls $\mathrm{OR}=2.45 ; 95 \%$ CI: 1.51 to 3.97$])$.

\section{Stress, Social Support, and Social Integration}

Stress is often associated with obesity and improper eating behaviors (Kouvonen,
Kivimaki, Cox, Cox, \& Vahtera, 2005; Takeda et al., 2004). A study by Diwan and colleagues (2004) among older Asian Indian immigrants looked at the predictors of positive and negative affect. They found that women were more prone to increased negative affect. If a person displayed greater satisfaction with friendships and had a cultural identity that was either bicultural or more American then these constructs predicted greater positive affect. Greater religious orientation and greater mastery predicted less negative affect. The modifiable constructs in this study that can be utilized in health education programs are social integration, increasing social support from friends, developing mastery and enhancing religiosity.

Kalra and colleagues (2004) conducted eight focus groups with Asian Indian American community to gauge perceptions about cardiovascular risk. They found six themes from these focus groups. The themes were knowledge about cardiovascular disease, health and cultural concerns about diet, physical activity, stress, acculturation concerns, and cardiovascular disease prevention ideas. They found that issues pertaining to stress and acculturation were common across all focus groups and recommended that these be addressed by health education programs.

\section{Acculturation}

Acculturation has been found to be a risk factor for several unhealthy behaviors among Asian Americans including obesity-related behaviors comprising of physical activity and fast-food consumption. A cross-sectional survey by Unger and colleagues (2005) was administered using AHIMSA acculturation scale (Unger, Gallaher, Shakib, Ritt-Olson, Palmer \& Johnson, 2002) among students in sixth and seventh grades from Asian-American and Hispanic communities. Acculturation to the US was found to be significantly associated with a lower frequency of physical activity participation and a higher frequency of fast-food consumption. It was suggested that health promotion programs be developed for acculturating families that encourage physical activity and healthy diets among youth. 
In a cross-sectional self-reported telephone survey of middle aged and older Asian Indian immigrants in the US, Jonnalagadda and Diwan (2005) gathered information about acculturation, behavioral risk factors, body mass index, chronic disease prevalence, depression, perceived control, quality of social support, and self-rated health.

The study found that $52 \%$ reported normal weight, $41 \%$ reported being vegetarians, $55 \%$ reported performing aerobic activity in daily life, and 5\% reported being smokers. The most common reported chronic diseases were hypertension (31\%) and diabetes (18\%). Being young, having lived in The US longer, and identification with being an American were found to be associated with greater levels of physical activity. Being in higher income category, identification with being an American and depression were associated with higher fat intake.

Another study done with Chinese-American children, which even though is not specific to South Asian-American children but may be used to understand some of the factors that may play a role in the overall Asian culture. This study by Chen \& Kennedy (2005) found that a democratic parenting style, poor family communication, acculturation level of the mother, and family affective responses contributed to increased body mass index (BMI) in Chinese-American children. These factors may be important for South Asian-American children also and must be considered by health education program planners.

\section{United States \\ Immigrant Status or Years in the} Immigrant status is also linked with overweight and obesity. A Canadian study found that people who were recent immigrants ( $\leq 10$ years) had significantly lower prevalence of overweight when compared with non-immigrants (Tremblay, Perez, Ardern, Bryan, \& Katzmarzyk, 2005). However, this difference did not remain over a longer period of time. Hence, more programs are needed for the group of South Asians who have lived for a longer time in the United States.

\section{Designing Interventions: Existing Interventions}

It is very unfortunate to note that not even a single health education or promotion intervention to reduce overweight or obesity specifically for South Asian American or even for Asian American community has been designed in the United States. In Asian countries, interventions designed to address overweight and obesity are also deficient. Only two interventions in children one implemented in China and another one in Japan were found in the literature. Both interventions have been done with obese children and none has been done for primary prevention. No interventions have been reported from South Asian countries. Perhaps, this is because the problem of overweight and obesity affects natives of these countries more when they immigrate to the United States (Singh, Tomlinson, Thomas, \& Sharma, 2001).

Jiang and colleagues (2005) in China designed an intervention for obese children in grades seven to nine and their parents. The intervention consisted of dietary behavior modification which entailed keeping a behavioral diary, home visits by the researcher to monitor the diary and cooking practices, modification of diet based on classifying foods as "red light" meaning high in fat and to be avoided, "yellow light" meaning intermediate and "green light" meaning low in fat and calories and good to eat. The intervention also aimed at increasing physical activity and adding structured exercise for 20-30 minutes per day for four days per week. The children were also instructed to reduce watching TV and reduce drinking sweetened beverages. No explicit behavioral theory has been used in the intervention. Using a randomized control design it was found that BMI there was significant decrease in BMI from 26.6 to 24.0, cholesterol by $5.5 \%$ and triglycerides by $9.7 \%$ in the experimental group.

Tanaka and colleagues (2005) designed an intervention for obese children in Japan. The intervention involved obese children from an elementary school and their parents. The intervention included a 20-30 minute tutorial about health behaviors from a pediatrician, filling out a form on dietary and exercise 
behaviors on each visit, and renewed commitment to change these behaviors. While no explicit theory has been reported in the article it seems the constructs similar to verbal reinforcement and goal setting from social cognitive theory (Bandura, 1986) were utilized in this intervention. The children were followed for 12 months and the predictors of weight loss that were found as significant were recommendation to consume higher energy from protein, greater decrease in relative body weight between first and second visit, higher age, and higher concentration of alanine aminotransferase at first visit.

\section{Recommendations for Interventions}

Health education and health promotion interventions for South Asian Americans can be at two levels, primary and secondary. Primary prevention efforts are focused on the whole population and aimed at preventing the onset of obesity. Secondary prevention efforts deal with individuals who are who were overweight or obese. Primary prevention interventions would be useful for children and adolescents in school settings and for recent immigrants in community settings. Secondary interventions need to be developed and implemented with both obese children in and out of school and adults in community settings. In community settings, religious organizations such as temples, mosques, or gurudwaras can serve as important venues for organizing such interventions. It has been found that religious organizations are important for South Asian Americans (Diwan, Jonnalagadda, \& Balaswamy, 2004). Schools should continue to be the setting of choice for children whereby interventions that include parents must be developed.

From the two interventions done in Asian countries, it was found that none of these explicitly operationalized a behavioral theory. In a review of 11 school-based primary interventions implemented and evaluated in the United States published between 1999 and 2004, Sharma (in press) found that eight (73\%) utilized a behavioral theory and social cognitive theory (Bandura, 1986) was the most popular. The interventions need to utilize behavioral theories which would enhance their efficiency, efficacy and effectiveness. Dallas and Burton (2004) based on a review of health care among racial and ethnic minority men underscored the need for culturally appropriate theories and constructs. It cannot be overemphasized that there is an ardent need for developing culturally appropriate and robust theories that explain and predict health behaviors among South AsianAmerican youth and adults.

Interventions need to target modifiable constructs and physical activity and nutrition behaviors seem to be most important. In addition the cultural and environmental factors of acculturation, social support, and social integration need to be addressed. A study by Bhattacharya and colleagues (1999) looked at the interrelationships among peer networks, parental attributes and drug use among AsianIndian adolescents born in the United Sates whose parents emigrated from India. The study found that the Asian Indian parents were aware of their children's academic performance, peer networks, and were concerned about the drug use in their children. All these characteristics led to a low prevalence of drug use. Similar constructs can be used in relation to developing obesity prevention programs in South Asian youth. Parental involvement and concern in this regard can be used for developing healthy behaviors with regard to physical activity and healthy eating in youth.

\section{Summary and Conclusions}

The purpose of this study was to develop culturally-relevant determinants that influence obesity and overweight among South Asian Americans and then develop a set of recommendations for designing culturallyappropriate interventions for this group. It was found that the rates of overweight and obesity have been increasing in this subpopulation and there is a need to implement a lower cut-off value for BMI to accurately determine overweight and obesity. With standard cut-offs for BMI, in adult males the rates of overweight were found to be as high as $57 \%$ and for females $38 \%$. In children, the rates for overweight ranged from $18 \%$ to $43 \%$ with obesity rates being around $24 \%$. The key determinants for overweight and obesity in South Asian 
Americans were found to be physical inactivity, dietary behaviors (consuming large portion sizes, less consumption of fruits and vegetables, large consumption of sweetened beverages), watching TV for long hours on a sustained basis, acculturation to the US, poor family communication, less social support, less social integration, stress, and longer years of living in the United States.

Despite the need for interventions in this subgroup to address rising rates of overweight and obesity not even a single primary or secondary level intervention has been developed in the United States. There is need for interventions both for children and adults. The interventions for children can be implemented in school settings while the interventions for adults need to be implemented in community settings and local religious organizations for South Asian Americans such as temples, mosques, or gurudwaras can be utilized in this direction. Parental involvement should be an important component of school-based interventions. There is a need to develop culturally robust behavioral theories that can be utilized with this subgroup of population.

\section{References}

Ahmed, S. M., \& Lemkau, J. P. (2000). Cultural issues in the primary care of south Asians. Journal of Immigrant Health, 2, 89-96.

Allison, D. B., Fontaine, K. R., Manson, J. E., Stevens, J., \& VanItallie, T. B. (1999). Annual deaths attributable to obesity in the United States. JAMA, 282, 1530-1538.

Aspinall, P. J. (2003). Who is Asian? A category that remains contested in population and health research. Journal of Public Health Medicine, 25, 91-97.

Barnes, J. S. \& Bennett, C. E. (2002). The Asian population: 2000. Census 2000 brief. Retrieved November 16, 2005, from http://www.census.gov/prod/2002pubs/c2kbr01-16.pdf

Bandura, A. (1986). Social foundations of thought and action. Englewood Cliffs, NJ: Prentice Hall.

Bhansali, A., Nagaprasad, G., Agarwal, A., Dutta, P., \& Bhadada, S. (2005). Does body mass index predict overweight in native Asian Indians? A study from a North Indian population. Annals of Nutrition and Metabolism, 50, 66-73.

Bhattacharya, G., Cleland, C., \& Holland, S. (1999). Peer networks, parental attributes, and drug use among Asian-Indian adolescents born in the United States. Journal of Immigrant Health, 1, 145154.

Chen, J. L., \& Kennedy, C. (2005). Factors associated with obesity in Chinese-American children. Pediatric Nursing, 31, 110-115.

Crawford, P. B., Story, M., Wang, M. C., Ritchie, L. D., \& Sabry, Z. I. (2001). Ethnic issues in the epidemiology of childhood obesity. Pediatric Clinics of North America, 48, 855-878.

Dallas, C., \& Burton, L. (2004). Health disparities among men from racial and ethnic minority populations. Annual Review of Nursing Research, 22, 77-100.

Davis, J., Busch, J., Hammatt, Z., Novotny, R., Harrigan, R., Grandinetti, A., et al. (2004). The relationship between ethnicity and obesity in Asian and Pacific Islander populations: a literature review. Ethnicity \& Disease, 14, 111-118.

Denney, J. T., Krueger, P. M., Rogers, R. G., \& Boardman, J. D. (2004). Race/ethnic and sex differentials in body mass among US adults. Ethnicity and Disease, 14, 389-398.

Deurenberg-Yap, M., \& Deurenberg, P. (2003). Is a re-evaluation of WHO body mass index cut-off values needed? The case of Asians in Singapore. Nutrition Reviews, 61, S80-S87.

Deurenberg, P., Deurenberg-Yap, M., \& Guricci, S. (2002). Asians are different from Caucasians and from each other in their body mass index/body fat per cent relationship. Obesity Reviews, 3, 141146.

Diwan, S., Jonnalagadda, S. S., \& Balaswamy, S. (2004). Resources predicting positive and negative affect during the experience of stress: A study of older Asian Indian immigrants in the United States. Gerontologist, 44, 605-614. 
Expert Panel on Detection, Evaluation, and Treatment of High Blood Cholesterol in Adults. (2001). Executive summary of the third report of the National Cholesterol Education Program (NCEP) expert panel on detection, evaluation, and treatment of high blood cholesterol in adults (Adult Treatment Panel III). Journal of the American Medical Association, 285, 2486-2497.

Gerberding, J. L., \& Marks, J. S. (2004). Making America fit and trim. Steps big and small. American Journal of Public Health, 94, 1478-1479.

Gordon-Larsen, P., Adair, L.S., \& Popkin, B. M. (2003). The relationship of ethnicity, socioeconomic factors, and overweight in U.S. adolescents. Obesity Research, 11, 121-129.

Gordon-Larsen P., Adair, L. S., \& Popkin, B. M. (2002). Ethnic differences in physical activity and inactivity patterns and overweight status. Obesity Research, 10, 141-149.

Gordon-Larsen, P., McMurray, R. G., \& Popkin, B. M. (1999). Adolescent physical activity and inactivity vary by ethnicity: The National Longitudinal Study of Adolescent Health. The Journal of Pediatrics, 135, 301-306.

Institute of Medicine. (2004). Preventing childhood obesity: Health in the balance. Washington, DC: National Academy Press.

Jiang, J. X., Xia, T. L., Greiner, T., Lian, G. L., \& Rsosenqvist, U. (2005). A two year family based behaviour treatment for obese children. Archives of Disease in Childhood. Retrieved October 1, 2005 from http://adc.bmjjournals.com/current.shtml

Jonnalagadda, S. S., \& Diwan S. (2005). Health behaviors, chronic disease prevalence and self-rated health of older Asian Indian immigrants in the U.S. Journal of Immigrant Health, 7, 75-83.

Jonnalagadda, S. S., Diwan, S., \& Cohen, D. L. (2005). U.S. Food Guide Pyramid food group intake by Asian Indian immigrants in the U.S. The Journal of Nutrition, Health, \& Aging, 9(4), 226-31.

Kandula, N. R., \& Lauderdale, D. S. (2005). Leisure time, non-leisure time, and occupational physical activity in Asian Americans. Annals of Epidemiology, 15, 257-265.

Kalra, P., Srinivasan, S., Ivey, S., \& Greenlund, K. (2004). Knowledge and practice: The risk of cardiovascular disease among Asian Indians. Results from focus groups conducted in Asian Indian communities in Northern California. Ethnicity \& Disease, 14, 497-504.

Kar, S. B., Campbell, K., Jimenez, A., \& Gupta, S. R. (1995). Invisible Americans: An exploration of Indo-American quality of life. Amerasia Journal, 21(3), 25-52.

Kouvonen, A., Kivimaki, M., Cox, S. J., Cox, T., \& Vahtera, J. (2005). Relationship between work stress and body mass index among 45,810 female and male employees. Psychosomatic Medicine, 67, 577-583.

Lauderdale, D. S., \& Rathouz, P. J. (2000). Body mass index in a US national sample of Asian Americans: Effects of nativity, years since immigration and socioeconomic status. International Journal of Obesity, 24, 1188-1194.

Misra, K. B., Endemann, S. W., \& Ayer, M. (2005). Leisure time physical activity and metabolic syndrome in Asian Indian immigrants residing in northern California. Ethnicity \& Disease, 15, 627-634.

Misra, R., Patel, T. G., Davies, D., \& Russo, T. (2000). Health promotion behaviors of Gujurati Asian Indian immigrants in the United States. Journal of Immigrant Health, 2, 223-230.

Robinson, T. N., \& Killen, J. D. (1995). Ethnic and gender differences in the relationships between television viewing and obesity, physical activity, and dietary fat intake. Journal of Health Education, 26, S91-S98.

Sharma, M. (in press). School-based interventions for childhood and adolescent obesity. Obesity Reviews.

Singh, R. B., Tomlinson, B., Thomas, G. N., \& Sharma, R. (2001). Coronary artery disease and coronary risk factors: The South Asian paradox. Journal of Nutritional and Environmental Medicine, 11, 43-51.

Steering Committee of the International Diabetes Institute, WHO Collaborating Centre for the Epidemiology of Diabetes Mellitus and Health Promotion for Non-communicable Diseases. 
(2000). The Asian perspective: Redefining obesity and its treatment. Melbourne: Health Communications Australia Private Limited.

Stettler, N., Elliott, M. R., Kallan, M. J., Auerbach, S. B., \& Kumanyika, S. K. (2005). High prevalence of overweight among pediatric users of community health centers. Pediatrics, 116, e381-e388.

Takeda, E., Terao, J., Nakaya, Y., Miyamoto, K., Baba, Y., Chuman, H., et al. (2004). Stress control and human nutrition. The Journal of Medical Investigation, 51, 139-45.

Tanaka, S., Yoshinaga, M., Sameshima, K., Nishi, J., Kono, Y., Nomura, Y., et al. (2005). Predictive factors in the success of intervention to treat obesity in elementary school children. Circulation Journal, 69, 232-236.

Thorpe, L. E., List, D. G., Marx, T., May, L., Helgerson, S. D., \& Frieden, T. R. (2004). Childhood obesity in New York City elementary school students. American Journal of Public Health, 94, 1496-1500.

Tremblay, M. S., Perez, C. E., Ardern, C. I., Bryan, S. N., \& Katzmarzyk, P. T. (2005). Obesity, overweight and ethnicity. Health Reports, 16, 23-34.

Unger, J. B., Gallaher, P., Shakib, S., Ritt-Olson, A., Palmer, P. H., \& Johnson, C. A. (2002). The AHIMSA Acculturation scale: A new measure of acculturation in a multicultural society. Journal of Early Adolescence, 22, 225-251.

Unger, J. B., Reynolds, K., Shakib, S., Spruijt-Metz, D., Sun, P., \& Johnson, C. A. (2004). Acculturation, physical activity, and fast-food consumption among Asian-American and Hispanic adolescents. Journal of Community Health, 29, 467-481.

United States Census Bureau. (1990). 1990 Census. Retrieved November 16, 2005, from http://www.census.gov/main/www/cen1990.html

United States Census Bureau. (2005). 2000 Census. Summary file 1. Retrieved November 16, 2005, from http://www.census.gov/Press-Release/www/2001/sumfile1.html

United States Department of Health \& Human Services. (2001). The Surgeon General's call to action to prevent and decrease overweight and obesity. Rockville, MD: Office of the Surgeon General. Retrieved on November 15, 2005, from http://www.surgeongeneral.gov/topics/obesity/calltoaction/CalltoAction.pdf

Vikram, N. K., Misra, A., Pandey, R. M., Dudeja, V., Sinha, S., Ramadevi, J., et al. (2003). Anthropometry and body composition in northern Asian Indian patients with type 2 diabetes: Receiver operating characteristics (ROC) curve analysis of body mass index with percentage body fat as standard. Diabetes, Nutrition \& Metabolism, 16, 32-40.

Walker, S., Sechrist, K., \& Pender, N. (1996). The health promotion lifestyles profile II. Omaha, NE: University of Nebraska Medical Center.

Wang, J., Thornton, J. C., Burastero, S., Shen, J., Tanenbaum, S., Heymsfield, S. B. et al. (1996). Comparisons for body mass index and body fat percent among Puerto Ricans, blacks, whites and Asians living in the New York City area. Obesity Research, 4, 377-384.

Author Information

Manoj Sharma, MBBS, CHES, Ph.D.

Associate Professor

Health Promotion \& Education

University of Cincinnati

526 Teachers College

PO Box 210002

Cincinnati, OH 45221-0002

Ph.: 513-556-3878

Fax.: 513-556-3898

E-Mail: manoj.sharma@uc.edu

URL: http://www.cech.uc.edu/faculty staff.php?p=biographies_list\&cn=SharmaMJ 